ORIGINAL ARTICLE

\title{
Randomised controlled trial and economic evaluation of podophyllotoxin solution, podophyllotoxin cream, and podophyllin in the treatment of genital warts
}

\author{
C J N Lacey, R L Goodall, G Ragnarson Tennvall, R Maw, G R Kinghorn, P G Fisk, \\ S Barton, I Byren, for the Perstorp Pharma Genital Warts Clinical Trial Group*
}

*See acknowledgements

See end of article for authors' affiliations

Correspondence to: Dr C J N Lacey, Faculty of Medicine, Imperial College of Science, Technology and Medicine, Norfolk Place, London W2 IPG, UK; c.lacey@ic.ac.uk

Accepted for publication 9 March 2003

\begin{abstract}
Objectives: To evaluate the efficacy and cost effectiveness of self applied podophyllotoxin $0.5 \%$ solution and podophyllotoxin $0.15 \%$ cream, compared to clinic applied $25 \%$ podophyllin in the treatment of genital warts over 4 weeks.

Methods: We conducted a randomised controlled trial in 358 immunocompetent men and women with genital warts of 3 months' duration or less.

Results: In the principal analysis both podophyllotoxin solution (OR 2.93, 95\% Cl 1.56 to 5.50) and podophyllotoxin cream (OR $1.97,95 \% \mathrm{Cl} 1.04$ to 3.70 ) were associated with significantly increased odds of remission of all warts compared to podophyllin. We performed two further analyses. When subjects defaulting from follow up were assumed to have been cured odds of remission of all warts were also significantly increased both for podophyllotoxin solution (OR 3.04, 95\% Cl 1.68 to 5.49) and for podophyllotoxin cream (OR $2.46,95 \% \mathrm{Cl} 1.38$ to 4.40 ). When subjects defaulting from follow up were assumed not to have been cured odds of remission of all warts were significantly increased for podophyllotoxin solution (OR 1.92, 95\% Cl 1.13 to 3.27), but not for podophyllotoxin cream (OR $1.17,95 \% \mathrm{Cl} 0.69$ to 2.00 ). Local side effects were seen in $24 \%$ of subjects, and recurrence of warts within 12 weeks of study entry in $43 \%$ of all initially cleared subjects, without statistically significant differences between the treatment groups. Direct, indirect, and total costs were similar across the three treatment groups. Podophyllotoxin solution was the most cost effective treatment, followed by podophyllotoxin cream, with podophyllin treatment being the least cost effective.

Conclusions: Self treatment of anogenital warts with podophyllotoxin showed greater efficacy and cost effectiveness than clinic based treatment with podophyllin.
\end{abstract}

7 enital warts are one of the most frequent sexually transmitted diseases worldwide, occurring at incidence rates of $0.6 \%-1.2 \%$ in men and women aged 20-24 years. ${ }^{2}$ They represent overt clinical infection with human papillomavirus (HPV) 6 or HPV $11 .{ }^{3}$ A wide variety of treatments are in use, but failure of treatment and recurrence after initial clearance are seen with all treatments. ${ }^{4}$ The economic burden of the management of genital warts is substantial. In the United States there are estimated to be 500 000-1 million new cases annually with health costs exceeding $\$ 3.8$ billion. $^{5}$

The use of podophyllin resin, an extract of the root of Podophyllum sp, in alcoholic solution was first described as an effective therapy for genital warts in $1942 .{ }^{6}$ Podophyllin resin contains numerous compounds, but podophyllotoxin has been shown to be the principal active therapeutic component. ${ }^{7}$ Podophyllotoxin offers a number of advantages over podophyllin in treatment of genital warts including purity, stability, and lack of systemic toxicity. ${ }^{89}$ Podophyllotoxin was initially formulated as a solution and regimes for self treatment were developed.$^{10}$ While this preparation is eminently suitable as a treatment for penile warts such a liquid formulation is less practicable for self treatment of vulval and introital warts in women and for anal warts in either sex. Formulations of podophyllotoxin in cream and gel bases were therefore developed to facilitate self treatment at any anogenital site. ${ }^{11-13} \mathrm{~A}$ number of trials have also suggested superior efficacy of podophyllotoxin formulations compared to podophyllin, although these trials recruited modest numbers of subjects and not all of the differential treatment outcomes in these trials reached statistical significance. ${ }^{14-17}$ We therefore de- signed a larger study to compare the efficacy, tolerability, and also the cost effectiveness of self treatment with podophyllotoxin solution $0.5 \%$ (Warticon or Wartec7 solution), and with podophyllotoxin cream $0.15 \%$ (Warticon or Wartec7 cream), compared to clinic based treatment with podophyllin $25 \%$ in the treatment of anogenital warts.

\section{METHODS}

Patients

This was an open, randomised, controlled multicentre trial carried out in 11 sexually transmitted disease clinics in the United Kingdom. Inclusion criteria included age 18-65 years and current anogenital warts with a history of 3 months or less and no therapy in that time. Exclusion criteria included known HIV infection or immunosuppression, homosexual men with perianal warts, total lesional area $>400 \mathrm{~mm}^{2}$, any individual lesion with an area of $>100 \mathrm{~mm}^{2}$ intrameatal or vaginal warts, ulcerative or inflammatory STDs of the anogenital region, and pregnancy.

The three treatment arms were podophyllotoxin cream $0.15 \%$ and podophyllotoxin solution $0.5 \%$, both self applied twice a day for 3 consecutive days with 4 days off therapy, and podophyllin $25 \%$ in tincture of compound benzoin applied twice weekly in the clinic. Randomisation to treatment was stratified according to sex, and $\geqslant 10$ warts or $<10$ warts using treatment assignment envelopes for each stratum. All therapies were given for 4 weeks, or until clearance if this was earlier. Subjects were evaluated weekly for 4 weeks, and then at 12 weeks after trial entry if complete remission was obtained in the first 4 weeks. Local ethical approval for the 
Table 1 Baseline characteristics (figures given are numbers (\%))

\begin{tabular}{|c|c|c|c|c|c|}
\hline & $\begin{array}{l}\text { Podophyllin } \\
(n=116)\end{array}$ & $\begin{array}{l}\text { Podophyllotoxin cream } \\
\text { ( } n=118)\end{array}$ & $\begin{array}{l}\text { Podophyllotoxin solution } \\
(\mathrm{n}=120)\end{array}$ & $\begin{array}{l}\text { Total } \\
(\mathrm{n}=354)\end{array}$ & $\mathrm{p}$ Value \\
\hline Male & $60(52)$ & $60(51)$ & $62(52)$ & $182(51)$ & 0.9 \\
\hline$<10$ warts & $82(71)$ & $84(71)$ & $79(66)$ & 245 (69) & 0.6 \\
\hline White & 110 (95) & 111 (94) & 114 (95) & 335 (95) & 0.9 \\
\hline Smoker & 61 (53) & 70 (59) & $67(56)$ & $198(56)$ & 0.6 \\
\hline Circumcised & $3(3)$ & 1 (1) & $9(8)$ & $13(4)$ & 0.02 \\
\hline
\end{tabular}

trial was obtained from all participating institutions. Informed consent for the trial was obtained from all patients.

The sample size for the study was based on assumptions regarding complete remission rates of original warts for different treatment groups. Using a two sided $\chi^{2}$ test without continuity correction at $\alpha=5 \%$ and power $=80 \%$, and assuming the group with the highest efficacy $=80 \%$ and the minimum difference that was clinically important to detect was $20 \%$, then 83 patients analysable for efficacy were required per group-that is, 249 in total.

\section{Data}

At each study evaluation the number and location of warts were recorded and classified as those present at the study entry (original warts), or those newly occurring during the trial. Adverse events, either self reported or detected on examination, were recorded at each visit. A nurse together with the patient collected data, including information about the use of resources, at each visit.

\section{Analyses}

The primary outcome measure of the study was the complete remission of all anogenital warts present at study entry (original warts) after 4 weeks treatment. We investigated the effect of treatment on both original warts and the total number of warts, which included those newly occurring during the 4 weeks of the study (all warts). The percentage of patients with total clearance of all/original warts and the relative reduction in the number of all/original warts were considered. The effect of treatment on clearance of all/original warts was further analysed using logistic regression models, adjusting for the effects of sex, smoking status, and the number of warts at entry ( $<10$ or $\geqslant 10$ warts). The analyses presented are for the odds of having complete remission with podophyllotoxin treatment, compared to podophyllin.

The principal (or per protocol) analysis was of the population of subjects who either had a complete remission, or had documentation of four treatment cycles. We also performed further analyses with two different assumptions regarding the status of cure for subjects who defaulted or were lost to follow up - that is, by setting the missing values to be the number of warts at the last visit (this assumes everybody who defaulted was not cured-“worst case" scenario), or by setting the missing values to zero (this assumes everybody who defaulted was cured- "best case" scenario).

The economic analysis was performed from a general societal point of view. Owing to the short study duration discounting was not performed. We obtained information regarding provider remuneration of costs for outpatient visits from six of the units participating in this study and averaged these. Direct costs consisted of outpatient visits at clinics for which we attribute differing costs for an initial or a follow up visit, drug treatment and travelling costs for the patients. Costs for treatment of adverse events were included for patients who discontinued from the trial because of adverse reactions. Indirect costs related to production losses when patients were absent from work due to treatment of warts were calculated separately. These costs were estimated accord- ing to average incomes for men and women employees in the United Kingdom in 1998 and were analysed separately. ${ }^{18}$

\section{Assumptions for the economic analysis}

For patients who had a relapse of warts within 12 weeks, and for those patients who discontinued from study because of adverse events or lack of effect, the same direct and indirect costs as the average cost for all three treatments have been assumed and added to the actual costs calculated for each of these patients. For patients who discontinued for other reasons than adverse events or lack of effect, and who did not subsequently reattend, an assumption has been made that the remission and relapse rates for such patients falling outside the principal analysis population was the same as for patients evaluated in the principal analysis population.

\section{RESULTS}

We originally planned a study size of 300 and assumed that $20 \%$ of subjects would not provide analysable end point data, and therefore asked six centres to enrol 50 patients each. However, one centre never commenced enrolment, and a higher non-analysability rate of $30 \%$ was observed in the first 150 patients. We therefore expanded the study size to 350 and added a further six centres, each to recruit 25 patients. A total of 354 patients were entered according to study criteria and received treatment; 120 patients were randomised to podophyllotoxin solution, 118 to podophyllotoxin cream, and 116 to podophyllin. The study population comprised $182(51 \%)$ men, $95 \%$ were white, $56 \%$ were smokers, $69 \%$ had less than 10 genital warts, and $96 \%$ of males were uncircumcised. The characteristics of the subjects in the three treatment arms were well matched at entry (table 1), except that there were slightly more circumcised men in the podophyllotoxin solution arm (9, compared to podophyllin 3, podophyllotoxin cream $1, p=0.02) .276(78 \%)$ of patients completed the trial according to the protocol, the principal analysis populations being 96, 82, and 98 subjects in each of the podophyllotoxin solution, podophyllotoxin cream and podophyllin arms respectively. The only significant difference between the principal analysis population and defaulters was that smokers were over-represented in the latter group (52\% v 70\% respectively, $\mathrm{p}=0.004$ ).

Tables 2 and 3 present both the raw complete remission rates and odds of achieving remission, by treatment group and population (the principal analysis, worst case, and best case populations), for original warts and all warts respectively. Treatment was associated with the odds of remission, with increased odds for both podophyllotoxin solution (for original warts OR $2.88,95 \%$ CI 1.52 to 5.45 ; for all warts OR 2.93, 95\% CI 1.56 to 5.50 ) and for podophyllotoxin cream (for original warts OR 1.67, 95\% CI 0.89 to 3.15; for all warts OR 1.97, 95\% CI 1.04 to 3.70 ) compared to podophyllin. In the analysis where subjects defaulting from follow up were assumed to have been cured we again observed increased odds both for podophyllotoxin solution (for original warts OR 2.91, 95\% CI 1.59 to 5.34; for all warts OR 3.04, 95\% CI 1.68 to 5.49) and for podophyllotoxin cream (for original warts OR $2.14,95 \%$ CI 1.19 to 3.82 ; for all warts OR 2.46 , 95\% CI 1.38 to 4.40 ) 
Table 2 Complete remission of original warts

\begin{tabular}{|c|c|c|c|}
\hline Population* & $\begin{array}{l}\text { Podophyllin } \\
\%(95 \% \mathrm{CI})\end{array}$ & $\begin{array}{l}\text { Podophyllotoxin cream } \\
\%(95 \% \mathrm{Cl})\end{array}$ & $\begin{array}{l}\text { Podophyllotoxin solution } \\
\%(95 \% \mathrm{Cl})\end{array}$ \\
\hline \multicolumn{4}{|c|}{ (A) Expressed as \% of subjects } \\
\hline Principal analysis & $53.1 \quad(42.7$ to 63.2$)$ & 64.6 (53.3 to 74.9 ) & $75.0(65.1$ to 83.3$)$ \\
\hline "Worst case" & $44.8(35.6$ to 54.3$)$ & 44.9 (35.7 to 54.3$)$ & $60.0(50.7$ to 68.8$)$ \\
\hline "Best case" & $60.3(50.8$ to 69.3$)$ & $75.4(66.6$ to 82.9$)$ & $80.0(71.7$ to 86.7$)$ \\
\hline Population* & $\begin{array}{l}\text { Podophyllotoxin cream } \\
\text { Odds }(95 \% \mathrm{Cl})\end{array}$ & $\begin{array}{l}\text { Podophyllotoxin solution } \\
\text { Odds }(95 \% \mathrm{Cl})\end{array}$ & \\
\hline \multicolumn{4}{|c|}{ (B) Expressed as odds of remitting compared to podophyllin $(=1)$ by regression analyses $†$} \\
\hline Principal analysis & $1.67(0.89$ to 3.15$)$ & \multicolumn{2}{|c|}{$2.88(1.52$ to 5.45$)$} \\
\hline "Worst case" & $1.01(0.59$ to 1.96$)$ & \multicolumn{2}{|l|}{$1.96(1.15$ to 3.33$)$} \\
\hline "Best case" & 2.14 (1.19 to 3.82$)$ & \multicolumn{2}{|l|}{2.91 (1.59 to 5.34$)$} \\
\hline
\end{tabular}

Table 3 Complete remission of all warts

\begin{tabular}{|c|c|c|c|}
\hline Population* & $\begin{array}{l}\text { Podophyllin } \\
\%(95 \% \mathrm{CI})\end{array}$ & $\begin{array}{l}\text { Podophyllotoxin cream } \\
\%(95 \% \mathrm{CI})\end{array}$ & $\begin{array}{l}\text { Podophyllotoxin solution } \\
\%(95 \% \mathrm{Cl})\end{array}$ \\
\hline \multicolumn{4}{|c|}{ (A) Expressed as \% of subjects } \\
\hline Principal analysis & 46.9 (36.8 to 57.3$)$ & $62.2(50.8$ to 72.7$)$ & $70.2(59.9$ to 79.2$)$ \\
\hline "Worst case" & 39.7 (30.7 to 49.2$)$ & $43.2(34.1$ to 52.7$)$ & 54.2 (44.8 to 63.3$)$ \\
\hline "Best case" & $55.2(45.7$ to 64.4$)$ & $73.7(64.8$ to 81.4$)$ & $76.6(68.1$ to 83.9$)$ \\
\hline Population* & $\begin{array}{l}\text { Podophyllotoxin cream } \\
\text { Odds }(95 \% \mathrm{Cl})\end{array}$ & $\begin{array}{l}\text { Podophyllotoxin solution } \\
\text { Odds }(95 \% \mathrm{Cl})\end{array}$ & \\
\hline \multicolumn{4}{|c|}{ (B) Expressed as odds of not remitting compared to podophyllin $(=1)$ by regression analyses } \\
\hline Principal analysis & $1.97(1.04$ to 3.70$)$ & $2.93(1.56$ to 5.50$)$ & \\
\hline "Worst case" & $1.17(0.69$ to 2.00$)$ & $1.92(1.13$ to 3.27$)$ & \\
\hline "Best case" & $2.46(1.38$ to 4.40$)$ & 3.04 (1.68 to 5.49$)$ & \\
\hline
\end{tabular}

compared to podophyllin. These differences therefore reached statistical significance in all analyses for podophyllotoxin solution, but only reached statistical significance for podophyllotoxin cream in the best case analysis where defaulters were assumed to be cured, and in the principal analysis for all warts. In all analyses, males and those with fewer than 10 warts at baseline had significantly increased odds of remitting. Smoking was not associated with the odds of remission, except when considering all warts in the best case analysis when smokers had significantly increased odds of remission. As smokers were significantly over-represented among subjects who defaulted we do not assume this to be of relevance.

We measured the relative reduction in the number of original warts and all warts over the 4 week treatment period for the three treatment groups. For original warts podophyllotoxin solution $(90.0 \%, 95 \%$ CI 85.3 to 94.6$)$ was significantly superior to podophyllin $(76.2 \%$, 95\% CI 67.4 to 85.1$)$ and podophyllotoxin cream $(75.4 \%, 95 \%$ CI 66.5 to 84.3$)$, whereas for all warts podophyllotoxin solution $(83.7 \%$, 95\% CI 77.0 to $90.4)$ was only significantly better than podophyllin $(62.2 \%$, 95\% CI 46.6 to 77.7 ) (podophyllotoxin cream $64.1 \%$, 95\% CI 48.1 to 80.2 ).

Local side effects were seen in $33 \%, 24 \%$, and $17 \%$ of the podophyllotoxin solution, cream, and podophyllin groups and ulceration in $18 \%, 12 \%$, and $10 \%$, respectively. Forty five per cent of subjects who were clear of warts at 4 weeks returned for a 12 week follow up or earlier in case of relapse. Relapse rates of $15 / 33(45 \%)$ in the podophyllotoxin solution group, $12 / 22(55 \%)$ in the podophyllotoxin cream group, and 5/19

Table 4 Total average direct and indirect costs per patient, in $£$, 1998 prices

\begin{tabular}{lrrr}
\hline & Podophyllin & Podophyllotoxin cream & Podophyllotoxin solution \\
\hline Direct costs & & & \\
Outpatient visits & 172.82 & 118.44 & 120.20 \\
Transportation & 17.61 & 13.46 & 10.75 \\
Drugs & 2.44 & 18.26 & 15.47 \\
Adverse event increment & 1.41 & 10.63 & 12.81 \\
Relapse increment & 14.47 & 43.05 & 29.77 \\
Total direct costs & $\mathbf{2 0 8 . 7 5}$ & $\mathbf{2 0 3 . 8 4}$ & $\mathbf{1 8 9 . 0 0}$ \\
Indirect costs & & & \\
Absence from work & 299.15 & 276.26 & 254.18 \\
Adverse event increment & 2.45 & 18.44 & 22.23 \\
Relapse increment & 25.12 & 74.68 & 51.66 \\
Total indirect costs & $\mathbf{3 2 6 . 7 2}$ & $\mathbf{3 6 9 . 3 8}$ & $\mathbf{3 2 8 . 0 7}$ \\
Total costs & $\mathbf{5 3 5 . 4 7}$ & $\mathbf{5 7 3 . 2 2}$ & $\mathbf{5 1 7 . 0 7}$ \\
\hline
\end{tabular}


Table 5 Cost effectiveness of the treatment alternatives (average cost effectiveness rates) for complete remission (CR) with $95 \%$ confidence intervals $(\mathrm{Cls})$ for all warts, principal analysis population, in $£, 1998$ prices

\begin{tabular}{llll}
\hline & Podophyllin & $\begin{array}{l}\text { Podophyllotoxin } \\
\text { cream }\end{array}$ & $\begin{array}{l}\text { Podophyllotoxin } \\
\text { solution }\end{array}$ \\
\hline Complete remission rates & $46.9 \%$ & $62.2 \%$ & $70.2 \%$ \\
Cls for CRs & 36.8 to 57.3 & 50.8 to 72.7 & 59.9 to 79.2 \\
Total average direct costs per patient & 208.75 & 203.84 & 189.00 \\
Direct costs/CR & $\mathbf{4 4 5 . 1 0}$ & $\mathbf{3 2 7 . 7 2}$ & $\mathbf{2 6 9 . 2 3}$ \\
Cls for direct costs/CR & $\mathbf{3 6 4 . 3 1}$ to $\mathbf{5 6 7 . 2 6}$ & $\mathbf{2 8 0 . 3 9}$ to $\mathbf{4 0 1 . 2 6}$ & $\mathbf{2 3 8 . 6 4}$ to $\mathbf{3 1 5 . 5 2}$ \\
Total average direct and indirect costs per patient & 535.47 & 573.22 & 517.07 \\
Total costs/CR & $\mathbf{1 1 4 1 . 7 2}$ & $\mathbf{9 2 1 . 5 8}$ & $\mathbf{7 3 6 . 5 7}$ \\
Cls for total costs/CR & $\mathbf{9 3 4 . 5 0}$ to & $\mathbf{7 8 8 . 4 8}$ to & $\mathbf{6 5 2 . 8 7}$ to $\mathbf{8 6 3 . 2 3}$ \\
& $\mathbf{1 4 5 5 . 0 7}$ & $\mathbf{1 1 2 8 . 3 9}$ & \\
\hline
\end{tabular}

$(26 \%)$ in the podophyllin group were observed. These differences were not statistically significant. We suggest these figures should be regarded as merely descriptive because of (a) the high proportion of defaulters in each group, and (b) the selection bias for re-attendance if further warts occurred.

\section{Economic results}

We obtained information regarding provider remuneration of costs for outpatient visits from six of the units participating in this study. We found that in 1998 the national average for an initial visit was around $£ 70$, with a range of costs from $£ 110$ to $£ 41$. The data showed that a follow up visit cost one third less than an initial visit. Table 4 shows the average direct, indirect, and total costs which were of a similar order across the three treatment groups. The average cost effectiveness of the treatment alternatives in terms of the costs per complete remission for the principal analysis population is shown in table 5. The results from this analysis show a hierarchy of cost effectiveness. Podophyllotoxin solution emerges as the most cost effective treatment, followed by podophyllotoxin cream, with podophyllin treatment being the least cost effective.

\section{DISCUSSION}

This is one of the largest randomised trials of treatments for genital warts yet reported. Its size, design, and multicentre nature make it likely that the results are a reasonable reflection of treatment outcomes for first episode genital warts in clinical practice. The patient population was mainly heterosexual, $96 \%$ of males were uncircumcised as is usual in the United Kingdom, and the majority of lesions in these men were subpreputial or on the distal penis. The three treatment arms were well matched at entry with no significant differences of relevance.

Although podophyllotoxin solution and gel are generally available at $0.5 \%$ strength, evaluations of podophyllotoxin cream have reported the use of $0.5 \%, 0.3 \%$, and $0.15 \%$ strengths. ${ }^{11}{ }^{12} 17$ Podophyllotoxin $0.3 \%$ cream appeared to be associated with a higher frequency of adverse events than $0.15 \%$ cream, and it was this latter licensed preparation that we studied. ${ }^{12}$ Our data can be compared with other published comparative trials of podophyllin and podophyllotoxin solution and cream. ${ }^{112}{ }^{14-17}$ We found generally similar clearance rates and differences in response rates between the different treatments to the published literature, although the numbers of subjects we studied was larger than those previously reported.

Patients with genital warts in clinical trials not infrequently default from follow up, which previous reports have observed. ${ }^{12}{ }^{14}$ We explored ways of utilising the data set in a manner where differing assumptions could be made about these "missing values." Sexually transmitted infections in general, and genital warts in particular, have been shown to be associated with psychological morbidity and concepts of shame. ${ }^{19}$ The clinicians who conducted the study were therefore of the opinion that defaulters were more likely to be cured than have persisting disease. The best case analysis therefore has substantial justification, and approaches the real life situation. We also present the response rates for the podophyllotoxin preparations in a novel manner as odds ratios by multivariate regression compared to the efficacy of podophyllin. This illustrates these comparisons (for example, for all warts in the best case analysis) in quite a striking manner, with podophyllotoxin solution and cream being 3.0 and 2.5 times more likely to produce cure than podophyllin. Podophyllotoxin solution was usually associated with numerically better cure rates than podophyllotoxin cream although in none of the regression analyses did this reach significance. Considering that we were comparing a $0.5 \%$ podophyllotoxin formulation with a $0.15 \%$ formulation the degree of similarity in treatment effects is of note. Although podophyllotoxin solution emerged as significantly superior to podophyllin in all regression analyses, podophyllotoxin cream was only statistically significantly better than podophyllin in the principal analysis for all warts and the best case analysis. Even larger trials than ours would be needed to settle this latter issue definitively. The data with regard to treatment side effects are suggestive of a correlation between side effects and efficacy, as has been observed previously, although the rates of side effects we observed were not statistically different between treatments. ${ }^{16}$ Side effects were not a limiting factor for treatments within the trial. Recurrence rates after individual treatments are crucial to overall clinical efficacy in real life. Our ability to reach conclusions about differences in recurrence rates was limited by the rate of patient default we observed at the 12 week visit, and we do not ascribe any significance to these data.

The economic evaluation was also complicated by the frequency of discontinuations during treatment and the reduced proportion of previously cleared patients who returned for the last follow up visit. Health economic analyses sometimes use disease free or healthy days as an effectiveness measure. ${ }^{20}$ In such studies of genital wart therapy it is not possible to obtain data for disease free days in all patients, and we therefore chose to use complete remission of all warts as the most appropriate effectiveness measure. Arguments can be made concerning the relevance of including indirect costs in such evaluations. ${ }^{21}{ }^{22}$ In this study the final results regarding which treatments were more cost effective do not differ whether indirect costs are included or not.

In economic evaluations both average costs, effects, and cost effectiveness should be demonstrated, as well as the marginal rates - that is, the additional cost per additional unit of the effect expressed as the marginal cost effectiveness rate. In the main economic analysis the total costs were lower for one of the evaluated drugs (podophyllotoxin solution) compared 
with the comparator drug (podophyllin solution) while its treatment effects were superior. It is therefore not necessary nor meaningful to estimate the marginal cost effectiveness rates for podophyllotoxin solution because it is clear that this alternative is more favourable. For podophyllotoxin cream the marginal cost in the main analysis was higher (£37.75) (table $4)$, but with a better clinical effect expressed as complete remission rate $(62.2 \%$ compared with $46.9 \%)$ (table 5 ) resulting in a marginal cost effectiveness rate of $£ 246.73$ per further cured patient. Podophyllotoxin cream is therefore a cost effective alternative compared with podophyllin solution since the cost of curing one further patient with podophyllotoxin cream is considerably lower than the average cost of curing one patient with podophyllin. In these analyses we have also used the confidence intervals for the complete remission rates associated with the three treatment alternatives as a form of sensitivity analysis. Although economic analyses are not usually evaluated with formal tests of statistical significance, there appears to be a hierarchy of total costs per complete remission with podophyllotoxin solution as the most cost effective and podophyllin as the least cost effective. It is believed that clinicians and patients arrive at choices between podophyllotoxin solution and cream on the grounds that podophyllotoxin cream is a more acceptable treatment for patients with "non-penile anogenital warts." Although it seems common sense that the superior ease of application of cream in less accessible anogenital sites would result in superior acceptability and perhaps effectiveness this has not been formally demonstrated. In the light of this assumption we suggest that the strategy of using podophyllotoxin solution for penile warts and podophyllotoxin cream for other anogenital warts is a cost effective one.

A few previous economic analyses of genital wart therapy have been published. ${ }^{23-25}$ As in our work, these studies illustrated that one of the central determinants of overall costs is the frequency of clinic visits, and this is inherently reduced with patient applied therapy. An economic evaluation should preferably reflect real clinical practice and it is therefore necessary to identify resource use for the purposes of the trial itself. ${ }^{26}$ In our trial the patients using podophyllotoxin were asked to attend every week. Assuming only two visits, one at the start of treatment and one after 4 weeks, as in normal clinical practice, would reduce total average costs for patients treated with podophyllotoxin solution and cream by $24 \%$ and $22 \%$, respectively.

Although self treatment regimens were developed and analysed some years ago, ${ }^{10}$ it is only recently that such therapies have become widely available. Podophyllotoxin is now marketed as a solution in many countries worldwide, and also as a cream formulation in Europe. In North America podophyllotoxin is also available in a $0.5 \%$ gel formulation, but the only published evaluation of this preparation in adults with genital warts suggested lower clearance rates that we observed for podophyllotoxin solution and cream. ${ }^{13}$ The primary clearance rates for podophyllotoxin observed in our study of $\sim 70 \%$ in both sexes compare well with other treatments. ${ }^{4}$ Both US and UK national guidelines for the treatment of genital warts continue to recommend the use of podophyllin..$^{28}$ Our demonstration that treatment of anogenital warts with podophyllotoxin solution and cream shows greater efficacy and cost effectiveness than clinic based treatment with podophyllin, as well the recognised pharmacological deficiencies of podophyllin, suggest that these guidelines may need further modification in due course. ${ }^{89}$ However, in clinical practice one of the foremost problems remains recurrence after therapy. Our study observed substantial recurrence rates similar to previous studies of podophyllin and podophyllotoxin, but also illustrates how recurrence after therapy diminishes cost effectiveness. Therefore, treatments, either single or combination, are needed which combine high rates of primary clearance with low recurrence rates. Recently interest has focused on immunological mechanisms of regression and it is possible that therapies associated with lower recurrence rates may be invoking such cytotoxic immune responses. ${ }^{29}$ If new treatments satisfying these clinical imperatives are developed they should be evaluated to address the issues of cost effectiveness that we have outlined.

\section{ACKNOWLEDGEMENTS}

Jeanette Sundberg and Mats Andersson were central to the original design of the study, and the initial analysis of the clinical outcome data. We also acknowledge the Perstorp Pharma Genital Warts Clinical Trial Group who devoted a large amount of time and effort in conducting and completing this study. As well as the authors of this paper they included Dr Sandy McMillan, Edinburgh Royal Infirmary; Dr Angela Robinson, Mortimer Market Centre, London; Dr Karen Rogstad, Chesterfield Royal Hospital; Dr Nathan Sankar, Newcastle General Hospital; and Dr Barbara Turner, Rotherham General Hospital.

Competing interests: CL has acted as a consultant to $3 \mathrm{M}$ Pharmaceuticals, GlaxoSmithKline, Merck and Xenova. RM has acted as an adviser to Perstorp Pharma, 3M Pharmaceuticals and Stiefel. None of the other authors are consultants for Stiefel, and have no financial interests in Stiefel or podophyllotoxin.

Funding: The study was funded by Perstorp Pharma, Lund, Sweden.

\section{CONTRIBUTORS}

CL was the PI for the study and lead author for the paper; CL, RM, GK, $\mathrm{PF}, \mathrm{SB}, \mathrm{IB}$, and GRT contributed to the design of the study; RG performed all the statistical analyses; GRT performed all the economic analyses; CL, RM, GK, PF, SB, and IB supervised the conduct of clinical trial; and all authors contributed to the write up.

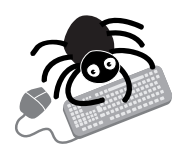

There are appendices to this paper on the ST website (www.stijournal.com/supplemental).

\section{Authors' affiliations}

C J N Lacey, Imperial College of Science, Technology, and Medicine, London, UK

R L Goodall, Medical Research Council Clinical Trials Unit, London, UK G Ragnarson Tennvall, IHE, The Swedish Institute for Health

Economics, Lund, Sweden

R Maw, Department of GU Medicine, Royal Victoria Hospital, Belfast, Northern Ireland, UK

G R Kinghorn, Department of GU Medicine, Royal Hallamshire Hospital, Sheffield, UK

P G Fisk, Department of GU Medicine, Leicester Royal Infirmary, Leicester, UK

S Barton, Department of GU Medicine, Chelsea and Westminster Hospital, London, UK

I Byren, GU Medicine Clinic, Radcliffe Infirmary, Oxford, UK

\section{REFERENCES}

1 PHLS, DHSS\&PS and the Scottish ISD(D)5 Collaborative Group. Sexually transmitted infections in the UK: new episodes seen at genitourinary medicine clinics, 1995 to 2000. London: Public Health Laboratory Service, 2001.

2 Persson G, Andersson K, Krantz I. Symptomatic genital papillomavirus infection in a community B incidence and clinical picture. Acta Obstet Gynecol Scand 1996;75:287-90.

3 Gross G, Ikenberg H, Gissmann L, et al. Papillomavirus infection of the anogenital region: correlation between histology, clinical picture and virus type. J Invest Dermatol 1985;85:147-52.

4 Beutner KR, Ferenczy A. Therapeutic approaches to genital warts. Am J Med 1997;102:28-37.

5 Centers for Disease Control, Division of STD Prevention. Sexually transmitted disease surveillance 1995. US Department of Health Services, Public Health Service. Atlanta: Centers for Disease Control and Prevention, September 1996

6 Kaplan IW. Condylomata acuminata. New Orleans Med Surg J 1942;94:388-90.

7 Von Krogh G, Maibach HI. Cutaneous cytodestructive potency of lignans. I. A comparative evaluation of influence on epidermal and dermal DNA synthesis and on dermal microcirculation in the hairless mouse. Arch Dermatol Res 1982;274:9-20. 
8 Fraser PA, Lacey CJN, Maw RD. Motion: podophyllotoxin is superior to podophyllin in the treatment of genital warts. J Europ Acad Dermatol Venereol 1993;2:328-34

9 Longstaff E, von Krogh G. Condyloma eradication: self-therapy with $0.15-0.5 \%$ podophyllotoxin versus $20-25 \%$ podophyllin preparations B an integrated safety assessment. J Regulatory Toxicol Pharmacol 2001:33:177-237

10 Von Krogh G. Penile condylomata acuminata: an experimental model for evaluation of topical self-treatment with $0.5 \%-1 \%$ ethanolic preparations of podophyllotoxin for 3 days. Sex Transm Dis 1981;8:179-84

11 Strand A, Brinkeborn RM, Siboulet A. Topical treatment of genital warts in men, an open study of podophyllotoxin cream compared with solution. Genitourin Med 1995:71:387-90.

12 Claesson $\mathbf{U}$, Lassus $\mathrm{A}$, Happonen $\mathrm{H}$, et al. Topical treatment of venereal warts: a comparative open study of popdophyllotoxin cream versus solution. Int J STD AIDS 1996;7:429-34.

13 Tyring S, Edwards L, Cherry LK, et al. Safety and efficacy of $0.5 \%$ podofilox gel in the treatment of anogenital warts. Arch Dermatol 1998; 134:33-8.

14 Lassus A. Comparison of podophyllotoxin and podophyllin in the treatment of genital warts. Lancet 1987;ii:512-3

15 Edwards A, Atma-Ram A, Thin RN. Podophyllotoxin $0.5 \%$ v podophyllin $20 \%$ to treat penile warts. Genitourin Med 1988;64:63-5.

16 Kinghorn GR, McMillan A, Mulcahy FM, et al. An open, comparative study of the efficacy of $0.5 \%$ podophyllotoxin lotion and $25 \%$ podophyllin solution in the treatment of condyloma acuminata in males and females. Int J STD AIDS 1993;4:194-9.
17 Hellberg D, Svarrer T, Nilsson S, et al. Self-treatment of female external genital warts with $0.5 \%$ podophyllotoxin cream (Condyline) vs weekly applications of $20 \%$ podophyllin solution. Int J STD AIDS 1995; $6: 257-61$

18 Central Statistical Office. Annual abstract of statistics 1999, no 135. London: The Stationery Office, 1999.

19 Maw RD, Reitano M, Roy M. An international survey of patients with genital warts: perceptions regarding treatment and impact on lifestyle. Int J STD AIDS 1998;9:571-8.

20 Drummond MF, O'Brien B, Stoddart GL, et al. Methods for the economic evaluation of health care programmes. Oxford: Oxford Medical Publications, 1997.

21 Drummond $M$. Cost-of-illness studies. A major headache? PharmacoEconomics 1992;2: 1-4.

2 Koopmanschap MA, Rutten FFH. Indirect costs in economic studies. Contronting the confusion. PharmacoEconomics 1993;4:446-54. 23 Mohanty KC. The cost-effectiveness of treatment of genital warts with podophyllotoxin. Int J STD AIDS 1994;5:253-6.

24 Strauss MJ, Khanna V, Koenig JD, et al. The cost of treating genital warts. Int J Dermatol 19́96;35:340-8.

25 Alam M, Stiller M. Direct medical costs for surgical and medical treatment of condylomata acuminata. Arch Dermatol 2001;137:337-41.

26 Drummond M, Davies L. Economic analysis alongside clinical trials. Revisiting the methodological issues. Int J Technol Assess Health Care 1991:7:561-73.

27 Centers for Disease Control and Prevention. 1998 Guidelines for treatment of sexually transmitted diseases. MMWR 1998;47(No RR-1):88-95

28 http://www.mssvd.org.uk/CEG/ceguidelines.htm

29 Coleman N, Birley HD, Renton AM, et al. Immunological events in regressing genital warts. Am J Clin Pathol 1994;102:768-74.

\section{$\mathrm{ECHO}$}

\section{Pericardial effusion easily misdiagnosed in HIV positive patients with lyphodystrophy}

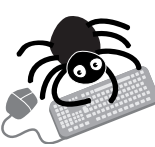

Please visit the Sexually Transmitted Infections website [www stijournal.com] for link to this full article.
$\mathrm{H}$ IV positive patients, suspected of having pericardial effusion, should undergo further investigation to avoid potentially fatal consequences, warn German researchers. The researchers draw attention to the case of a 52 year old HIV positive man (stage C3), who was being treated with a combination of nelfinavir, nevirapine, and stavudine. He had no history of heart disease, but was admitted because of breathing difficulties on exertion. On admission, his CD4 count was 81 cells $/ \mathrm{mm}^{3}$ and his viral load was $<50$ copies $/ \mathrm{ml}$. But he had evidence of lypodystrophy syndrome, including reduced subcutaneous fat, increased fatty tissue around the intestine, and increased serum lipid concentrations.

An echocardiogram 10 months previously had indicated diastolic dysfunction and a $4 \mathrm{~mm}$ wide epicardial space, which a second echocardiogram showed, had increased to $18 \mathrm{~mm}$, but there were minimal changes to ventricular function.

Because fatty tissue deposits around the heart and pericardial effusion are difficult to distinguish on echocardiography, magnetic resonance imaging was also carried out-computer tomography may be used instead. This clearly showed pericardial fat, but no fat deposits in the myocardium.

A puncture of the epicardial adipose tissue, on the assumption that it is pericardial effusion, risks perforating the ventricles, with potentially fatal consequences, say the authors. Although much more expensive, additional resonance imaging or computer tomography could save lives, they conclude.

\ Heart 2002; 87:e4 (http://www.heartjnl.com/cgi/content/full/87/5/e4) 